\title{
Kaputu Kinjila e o sócio dele Kambaxi Kiaxi: tradução para o italiano de uma fábula angolana de José Luandino Vieira
}

Elisa Scaraggi

Resumo: A ideia de publicar aqui uma amostra de tradução de Luandino Vieira para o italiano responde a uma dupla finalidade: apresentar a obra desse grande escritor, que aqui assume o papel de narrador de fábulas, e ao mesmo tempo uma tradução que não achate a diferença, que não apague o outro no texto. Os parágrafos iniciais contextualizam o argumento oferecendo algumas noções básicas sobre a importância da cultura oral tradicional na escrita dos africanos lusófonos, mas também apontam para a originalidade e atualidade do projeto literário de Luandino Vieira. Na segunda parte do texto, após um breve comentário sobre as escolhas de tradução, é reproduzido o texto original de Kaputu Kinjila e o sócio dele Kambaxi Kiaxi e, a seguir, sua tradução para o italiano.

Palavras-chave: Luandino Vieira, infância, fábula, tradições orais, tradução.

«A minha relação de escritor com as crianças é a minha relação de escritor comigo próprio, porque eu continuo uma criança $a^{1}$.»

Luandino Vieira

1 Dos Santos, Joelma G. "A Literatura se alimenta de Literatura. Ninguém pode chegar a escritor se não foi um grande leitor." Entrevista com José Luandino Vieira. Universidade Federal de Pernambuco: Revista Investigações Vol $21 n^{\circ} 1$. Janeiro 2008, edição digital. 
Ao nos aproximarmos da literatura angolana contemporânea, não podemos ignorar a grande influência que tiveram, sobre o imaginário e a escrita dos seus autores, os provérbios, os missosso e as fábulas através dos quais transmitiu-se durante séculos a cultura de um povo fortemente vinculado a uma tradição literária oral. Esses elementos, à luz das mudanças desenvolvidas na sociedade, aparecem constantemente nas obras dos escritores angolanos e podem ser vistos como uma forma de resistência e de busca de uma identidade própria em contraposição à hegemonia cultural ocidental.

Além de incorporar temáticas e personagens ligados ao âmbito tradicional e à realidade local, a literatura africana de língua portuguesa forjou uma língua nova, híbrida, para melhor se adaptar a essa realidade que pretendia descrever.

Nesse contexto, a obra de José Luandino Vieira é um exemplo surpreendente. Nela, a língua do colonizador sofre modificações tanto lexicais quanto sintáticas e gramaticais. Em um ato de subversão que é também, mas não apenas, linguístico, a língua popular falada em Luanda vai minando irreversivelmente o português padrão, durante tantos séculos imposto aos angolanos. Nas palavras de Costa Andrade (ANDRADE, 1980, p. 26), "quanto à utilização veicular da língua (...) trata-se aqui de uma forma de combate, de penetração no seio das posições inimigas".

A língua de Luandino Vieira reflete a complexidade e a multiplicidade da sociedade angolana, filha da miscigenação, numa terra de negros, mestiços e brancos. A língua é parte integrante da estrutura profunda do texto e não se limita a estar presente somente nas falas dos personagens ou, dito de outra forma, ela também é personagem.

Aos que questionam o fato que um escritor profundamente revolucionário e anticolonialista siga usando a língua - ainda que africanizada do colonizador, Luandino responde afirmando que o uso do português é uma escolha consciente e deliberada: é um troféu de guerra que os angolanos podem brandir com orgulho.

A produção de Luandino Vieira é vasta e complexa. Mas, se quisermos achar um fio condutor que a percorre, podemos individualizá-lo na memória. Trata-se de uma memória "baseada numa vivência muito intensa, muito determinada, muito funda, eu ia dizer até muito séria para uma criança". 2

2 Dos Santos, Joelma G. Entrevista citada. 
A infância em um musseque de Luanda, as relações humanas que ele pôde observar ali, tudo foi constituir esse material bruto que o escritor reelaborou nas suas histórias e romances. A infância é, e não por acaso, um tema recorrente das narrativas de Luandino. As personagens de No antigamente, na vida e de $A$ cidade e a infância são quase todas crianças. As crianças têm um papel fundamental em algumas histórias de Luuanda (especialmente em A galinha e o ovo). Os quatro de Nós, os de Makulusu são amigos desde criança.

No entanto, no livro cuja tradução é aqui apresentada, Luandino Vieira pela primeira vez dirige-se a um público infantil. Esse livro intitula-se Kaputu Kinjila e o sócio dele Kambaxi Kiaxi: uma fábula angolana e se insere em um projeto do escritor que engloba outras seis fábulas, todas acompanhadas das ilustrações do próprio autor.

Lembramos que já em 2006 foi publicada $A$ guerra dos fazedores de chuva com os caçadores de nuvens com o subtítulo provocatório de Guerra para crianças. Esse livro, também ilustrado por Luandino, conta, sob a forma de um mussosso tradicional, uma das muitas batalhas disputadas em solo angolano. Contudo, esta história, embora publicada à parte, já integrava a narrativa de $O$ livro dos rios, primeiro capítulo de uma trilogia intitulada De rios velhos e guerrilheiros com a qual Luandino Vieira retornou à cena literária depois de anos de ausência.

Voltando a Kaputu Kinjila e o sócio dele Kambaxi Kiaxi, a fábula segue a estrutura dos contos tradicionais angolanos. A escolha dos personagens é o primeiro sinal da tentativa de se colocar na mesma trajetória dos narradores tradicionais. O cágado (Kambaxi Kiaxi, nesse caso) é, de fato, um animal típico das histórias populares angolanas e traz em si diversos valores e habilidades já convencionados. Apesar de ser um animal com pouca força e sem recursos físicos particulares, o cágado, no desfecho dos contos, geralmente sai vitorioso. Isso

porque o imaginário das comunidades sempre criou situações em que os pequeninos podem, através da inteligência, da agilidade e da argúcia, suplantar antagonistas poderosos (DA COSTA 1989, p. 112).

O mesmo papel do cágado é interpretado, em outras histórias e em outras regiões geográficas da África, por outros animais quais o coelho, a aranha ou o sapo. Além das histórias que o próprio Luandino provavelmente deve ter escutado quando criança, sabemos com certeza que, há muito tempo, o autor dedica-se à leitura do material escrito sobre a história de 
Angola durante e depois do período colonial ${ }^{3}$. É igualmente certo ${ }^{4}$ que o autor leu o livro Contos Populares de Angola do antropólogo suíço Héli Chatelain, a maior coletânea de contos redigidos em kimbundu e em inglês (traduzidos para o português apenas em 1964). Nessa enciclopédia do conto popular angolano, encontramos a história Nguadi Ni Mbaxi (CHATELAIN, 1964 , p. 410-412), na tradução portuguesa, A perdiz e a tartaruga. Vemos como a tradução portuguesa simplifica a história, salvando dela só o enredo básico. Isso resulta em uma visível redução do texto e na supressão de partes em versos que provavelmente no original eram pensadas para ser cantadas.

A história de Luandino, ao contrário, não apenas recupera a temática e os personagens, mas resgata também a estrutura dos contos, inserindo as estrofes em kimbundu. Além disso, ela termina com a frase Tenho dito, tradução da expressão em kimbundu Mahezu, com a qual os narradores ou griots costumam acabar as próprias narrativas, deixando transparecer que, além da função lúdica e de entretenimento da fábula, existe uma moral, uma advertência do mais velho à sua audiência.

Embora baseada na tradição, parece-nos que a fábula de Luandino traz muitas inovações e adapta-se ao tempo em que o autor escreve, tempo contraditório em que Angola, em nome do progresso, está vivenciando uma onda de capitalismo sem precedentes na história do país. Na parábola do pássaro Kaputu Kinjila que pretende enriquecer deslealmente prejudicando os mais fracos, no caso o cágado, e termina morrendo "com as algibeiras cheias de dinheiro" (VIEIRA, 2010, p. 14), esconde-se uma crítica áspera aos valores da sociedade atual.

Ao contrário de outros textos do mesmo autor, a fábula analisada não apresenta problemas de tradução de particular relevância. A maior preocupação será, então, tentar recriar a estrutura rítmica, que desenvolve um papel tão importante em uma cultura oral, e retransmitir as marcas identitárias do texto que são os sinais de sua angolanidade. Essa preocupação coloca-se na mesma linha da "ética da diferença" que os discursos

A este propósito, leia-se a já citada entrevista de Joelma Dos Santos.

4 A este propósito, leia-se o ensaio "De onde viemos, não há nada para ver": aspectos da oralidade em Nós, os de Makulusu, de José Luandino Vieira em A kinda e a misanga. Encontros brasileiros com a literatura angolana, São Paulo: Cultura Acadêmica, 2007. Nesse ensaio, Fabiana B. Carelli Marquezini individua na epígrafe do romance Nós, os de Makulusu uma citação da última das narrativas que compõem o livro de Chatelain. 
pós-coloniais sobre a tradução têm tentado articular (SELIGMANN-SILVA 2005, p. 216).

Temos que levar em conta que a língua italiana, e em particular a norma culta, a da literatura, recorre geralmente a construções verbais e sintáticas complexas, faz uso copioso de subordinadas e de figuras retóricas que lhe valem o apelativo de língua barroca. Para apreciar essas características, vejamos aqui um exemplo de texto infantil modelo para um público italiano. Trata-se de um trecho extraído de um volume de fábulas africanas recolhidas pelo antropólogo Paul Radin e publicadas na Itália com o prefácio do famoso escritor Italo Calvino (RADIN, 1955, p. 54). Olhemos para o incipit dessa fábula:

Allora viveva Kwaku Ananse, il ragno, e andò da Nyankonpon, il diodel-cielo, e gli chiese: - Nonno, prendi la tua pecora che si chiama Kra Kwame, quella che tieni in serbo per sacrificarla un sabato alla tua anima, e lascia che io la uccida e me la mangi, che in cambio vado a prenderti una bella ragazza ${ }^{5}$.

Vejamos agora a diferença com o incipit de Luandino e a sua tradução para o italiano.

\begin{tabular}{|l|l}
\hline Foi ontem. & Ė stato ieri. \\
O pássaro Kaputu Kinjila & L'uccello Kaputu Kinjila \\
morava no céu. & viveva nel cielo.
\end{tabular}

À diferença da ousadia da sintaxe do primeiro trecho citado, o começo da fábula de Luandino resulta quase lapidário. Notemos como, talvez influenciado por narradores em kimbundu, talvez querendo operar uma desconstrução do canônico texto complexo, Luandino narra a sua história numa sucessão de frases curtas, onde predomina a parataxe como recurso estilístico. Isso, além de resultar em uma escrita de fácil compreensão para os mais novos, também ajuda a construir um ritmo narrativo mais premente.

5 "Naquele tempo vivia Kwaku Ansane, a aranha, que foi até Nyankonpon, o deus-do-céu, e pediu-Ihe: -Avô, pega aquela sua ovelha que se chama Kra Kwane, aquela que você guardava para sacrificá-la um sábado à sua alma, e deixa que eu a mate e a coma, porque em troca eu vou procurar uma moça bonita para você." (Nossa tradução) 
O tradutor deverá manter essa estrutura sintática embora possa causar estranheza aos olhos e aos ouvidos do leitor italiano. Tendo como farol o ritmo interno da frase, a tradução, mesmo aquela das partes relativamente mais compridas, tende ao sintetismo e tenta manter o mesmo número de palavras por frase.

Vejamos aqui outro exemplo:

\begin{tabular}{|l|l|}
\hline Kaputu Kinjila viu & Kaputu Kinjila vide \\
Kambaxi Kiaxi. & Kambaxi Kiaxi. \\
Pensou: & Pensò: \\
"Faz tudo devagar. Pensa muito. & "Fa tutto così piano. Pensa tanto. \\
Fala pouco. & Parla poco. \\
É estúpido!" & È stupido!" \\
Lisonjeou-lhe: & Lo lusingò: \\
- Senhor Kambaxi Kiaxi, és um bom & - Signor Kambaxi Kiaxi, sei un bravo \\
pescador. Vamos ser sócios. Vamos & pescatore. Diventiamo soci. \\
ficar ricos! & Diventeremo ricchi! \\
\hline
\end{tabular}

Esse trecho apresenta também outra questão, a do gênero. Prestemos atenção ao uso dos adjetivos "estúpido" e "bom": Kambaxi Kiaxi, herói do conto, é de fato um cágado e não uma tartartuga, portanto na fábula sua personificação ganha automaticamente contornos masculinos. Em italiano, todavia, não existe um sinônimo ou equivalente masculino para tal animal. Mesmo assim, e correndo o risco de ir contra toda uma tradição fabulística na qual as tartarugas sempre foram sábias personagens femininas, decidimos manter o gênero masculino de Kambaxi Kiaxi e manter com consequência não apenas para a concordância dos adjetivos, mas também aquele Senhor (em italiano Signor) que o pássaro Kaputu Kinjila Ihe dirige mais de uma vez ao longo da narrativa.

Além de respeitar o peso específico de cada frase de Luandino, sem acrescentar nem tirar palavras, e além de respeitar a identidade de gênero dos personagens, o tradutor deverá manter também o estranhamento causado pelo uso de algumas palavras tipicamente angolanas.

Queremos aqui seguir as indicações de Walter Benjamin que, no célebre prefácio à tradução dos Tableaux parisiens de Baudelaire, já declarava que "o erro fundamental do tradutor consiste em este se agarrar ao estado em que por acaso se encontra a sua língua em vez de a submeter ao poderoso impulso das outras línguas" (BENJAMIN, 2008, p. 41). 
Não pretendemos aqui aproximar a fábula de nossa tradição literária, pelo contrário, queremos que nosso italiano se angolanize. Vejamos, por exemplo, como o apelativo Nga, termo angolano para "senhor/a" (equivalente ao brasileiro sinhô/ sinhá) fica no italiano sem nenhum tipo de explicação. Provavelmente o termo não será compreendido por muitos leitores, mas achamos importante deixar uma marca visível do kimbundu, língua que escorre subterrânea pelo texto inteiro. Diferente é o caso da palavra muzua (rede), já que ela apresenta-se mais vezes ao longo da fábula. Sua primeira aparição no texto em português coincide com a primeira aparição na versão italiana, porém, já da segunda vez, ela é substituída pelo substantivo italiano rete para facilitar a compreensão e evitar uma nota do tradutor ou um glossário.

O kimbundu reaparece, finalmente, na última página do volume em duas estrofes traduzidas - também na versão de Luandino - em uma nota de rodapé. Vejamos aqui em detalhe:

\section{Em kimbundu:}

Kalumbinga kia Kinjila/Kinjila uadiboto/Kalumbinga kia Kinjila/Kinjila uadibondo... / / Kia' xi, kia' xi/Kia bulu, kia mulenge.

Em português:

O corninho (esporão) do Kinjila / Kinjila perdeu o valor / O corninho (esporão) do Kinjila / Kinjila faliu... / /O que é da terra, é da terra / O que é do céu, é do vento.

Em italiano:

L'ossicino di Kinjila / Kinjila ha perso il coraggio / L'ossicino di Kinjila / Kinjila ha fallito / / ... Ciò che è della terra, è della terra / Ciò che è del cielo, è del vento.

Notemos como na versão italiana o mais específico esporão, em vez de "sperone" vira "ossicino" (ossinho), em uma tentativa de deixar o texto mais aprazível para as crianças. O termo sperone, aliás, tem em italiano uma forte conotação equestre e o seu uso nesse contexto poderia criar certa ambiguidade. 
A despeito da relativa simplicidade desse texto, persiste o espanto em constatar a dificuldade de devolver a alteridade da língua literária de Luandino Vieira para o italiano. O italiano, de fato, e ao contrário de outras línguas europeias, nunca prestou-se - se não talvez atualmente com a literatura dos migrantes de segunda geração - a acolher as dinâmicas rítmicas e sintáticas de outras línguas e escritas não canonizadas. Contudo, não há como negar o prazer em encarar esse desafio.

Aliás, estamos firmemente convencidos de que ampliar o horizonte cultural dos leitores italianos, especialmente dos mais jovens, levando até eles a voz de outros mundos distantes e distintos, pode contribuir com uma maior abertura diante do outro e à derrota da crescente xenofobia que se registra nos países europeus.

\section{Referências}

ANDRADE, Fernando da Costa. Literatura Angolana (opiniões). Lisboa: Edições 70, 1980.

BENJAMIN, Walter. A tarefa do tradutor em $A$ tarefa do tradutor de Walter Benjamin, quatro traduções para o português, organizadora Lucia Castello Branco. Fale/UFMG, Belo Horizonte: 2008.

CARELLI, Fabiana B. Marquezini. "De onde viemos, não há nada para ver": aspectos da oralidade em Nós, os de Makulusu, de José Luandino Vieira in A kinda e a misanga. Encontros brasileiros com a literatura angolana, São Paulo: Cultura Acadêmica, 2007.

CHATELAIN, Héli. Contos populares de Angola. Trad. M. Garcia da Silva. Lisboa: Agência Central do Ultramar, 1964

DOS SANTOS, Joelma G. A Literatura se alimenta de Literatura. Ninguém pode chegar a escritor se não foi um grande leitor." Entrevista a José Luandino Vieira. Universidade Federal de Pernambuco: Revista Investigações Vol $21 n^{\circ}$ 1. Janeiro 2008, edição digital. Consulta realizada em 15 de setembro de 2010.

RADIN, Paul. Fiabe africane. Torino: Giulio Einaudi Editore, 1955.

ROSÁRIO, Lourenço Joaquim da Costa. A Narrativa Africana de expressão oral: transcrita em português. Luanda: Angolê, 1989.

VIEIRA, José Luandino. Kaputu Kinjila e o sócio dele Kambaxi Kiaxi: uma fábula angolana. Leça da Palmeira: Editor Letras e Coisas, 2010. 


\begin{tabular}{|c|c|}
\hline $\begin{array}{c}\text { KAPUTU KINJILA } \\
\text { e o sócio dele KAMBAXI KIAXI }\end{array}$ & $\begin{array}{c}\text { KAPUTU KINJILA } \\
e \text { il suo socio KAMBAXI IAXI }\end{array}$ \\
\hline $\begin{array}{c}\text { Uma fábula } \\
\text { angolana }\end{array}$ & $\begin{array}{l}\text { Una favola } \\
\text { angolana }\end{array}$ \\
\hline $\begin{array}{l}\text { José Luandino } \\
\text { Vieira }\end{array}$ & $\begin{array}{l}\text { José Luandino } \\
\text { Vieira }\end{array}$ \\
\hline Para & Per \\
\hline $\begin{array}{l}\text { Nha Beba, } \\
\text { mais que tudo, } \\
\text { nossa Mãe. }\end{array}$ & $\begin{array}{l}\text { Nha Beba, } \\
\text { più di tutto, } \\
\text { nostra Madre. }\end{array}$ \\
\hline Foi ontem. & È stato ieri. \\
\hline O pássaro & L'uccello \\
\hline Kaputu Kinjila & Kaputu Kinjila \\
\hline morava no céu. & viveva nel cielo. \\
\hline 0 & La \\
\hline cágado & tartaruga \\
\hline Kambaxi Kiaxi & Kambaxi Kiaxi \\
\hline morava na & viveva nella \\
\hline lagoa. & laguna. \\
\hline $\begin{array}{l}\text { Kaputu Kinjila viu Kambaxi Kiaxi. } \\
\text { Pensou: }\end{array}$ & $\begin{array}{l}\text { Kaputu Kinjila vide Kambaxi Kiaxi. } \\
\text { Pensò: }\end{array}$ \\
\hline $\begin{array}{l}\text { "Faz tudo devagar. Pensa muito. } \\
\text { Fala pouco. }\end{array}$ & $\begin{array}{l}\text { "Fa tutto così piano. Pensa tanto. } \\
\text { Parla poco. }\end{array}$ \\
\hline É estúpido!" & È stupido!" \\
\hline Lisonjeou-Ihe: & Lo lusingò: \\
\hline $\begin{array}{l}\text { - Senhor Kambaxi Kiaxi, } \\
\text { és um bom pescador. }\end{array}$ & $\begin{array}{l}\text { - Signor Kambaxi Kiaxi, sei un } \\
\text { bravo pescatore. }\end{array}$ \\
\hline Vamos ser sócios. & Diventiamo soci. Diventeremo \\
\hline Vamos ficar ricos! & ricchi! \\
\hline
\end{tabular}




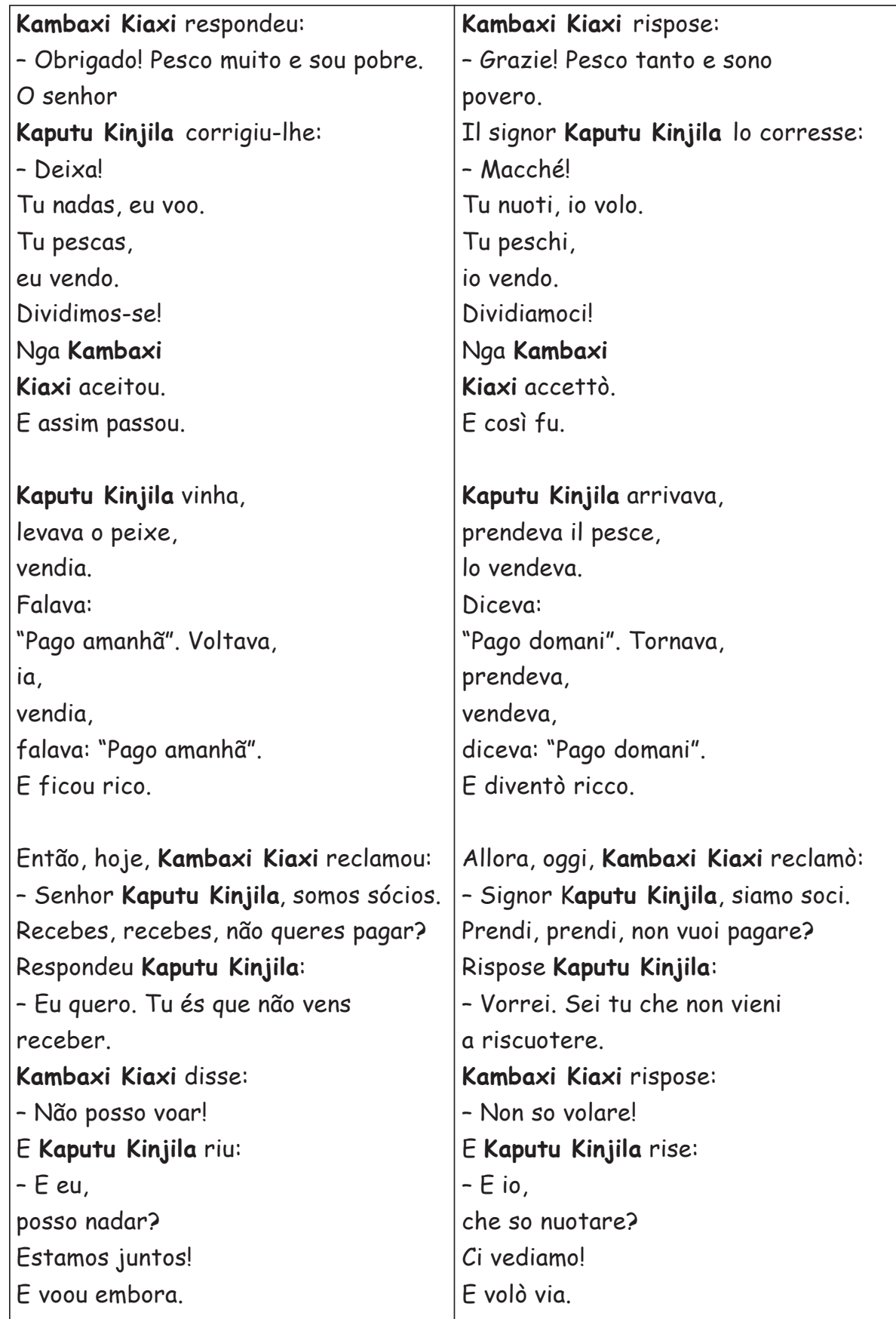




\begin{tabular}{|c|c|}
\hline Aí o senhor & Allora il signor \\
\hline Kambaxi Kiaxi pensou, pensou. & Kambaxi Kiaxi pensò, pensò. \\
\hline Chamou-lhe: & Lo chiamò: \\
\hline - Senhor & - Signor \\
\hline Kaputu Kinjila, desce ainda na & Kaputu Kinjila, scendi fino \\
\hline margem. & alla riva. \\
\hline Eu nado & Io nuoto \\
\hline até lá. & fino a lì. \\
\hline Kaputu Kinjila respondeu, zangado: & Kaputu Kinjila rispose, arrabbiato: \\
\hline - Ih! Para os caçadores me dispararem? & - Ih! Così i cacciatori mi sparano? \\
\hline - Desce, então, na canoa - & - Allora scendi fino alla canoa- \\
\hline disse Kambaxi Kiaxi. & disse Kambaxi Kiaxi. \\
\hline Kaputu Kinjila insultou-lhe: & Kaputu Kinjila lo insultò: \\
\hline - És parvo! & - Sei scemo! \\
\hline Não vês o jacaré? & Non vedi il coccodrillo? \\
\hline Então Kambaxi & Allora Kambaxi \\
\hline Kiaxi entrou na muzua cheia & Kiaxi entrò nella muzua piena \\
\hline de peixes & di pesci \\
\hline e gritou: & e gridò: \\
\hline - Senhor & - Signor \\
\hline Kaputu Kinjila, olha só & Kaputu Kinjila, guarda un po' \\
\hline na muzua! & nella rete! \\
\hline Quando viu a muzua cheia de & Quando vide la rete piena di \\
\hline peixes Kaputu & pesci Kaputu \\
\hline $\begin{array}{l}\text { Kinjila voou, agarrou, levou no ar } \\
\text { e gritou }\end{array}$ & $\begin{array}{l}\text { Kinjila volò, la afferrò, si alzò in } \\
\text { volo e gridò }\end{array}$ \\
\hline para a lagoa: & alla laguna: \\
\hline - Kambaxi Kiaxi, não pescas & - Kambaxi Kiaxi, non puoi più \\
\hline mais! & pescare! \\
\hline Tens de me pagar para devolver & Devi pagarmi se vuoi indietro \\
\hline a muzua. & la rete. \\
\hline Aí, & Allora, \\
\hline Kambaxi Kiaxi & Kambaxi Kiaxi sbucò in mezzo \\
\hline $\begin{array}{l}\text { saiu no meio dos peixes, meteu os } \\
\text { dedos nas malhas da muzua, agarrou as } \\
\text { pernas do Kaputu Kinjila. }\end{array}$ & $\begin{array}{l}\text { ai pesci, mise le dita tra } \\
\text { le maglie della rete, afferrò le zampe } \\
\text { di Kaputu Kinjila. }\end{array}$ \\
\hline
\end{tabular}




\begin{tabular}{|c|c|}
\hline E arrancou-lhe os esporões. & E gli strappò gli ossicini. \\
\hline Caíram na lagoa. & Caddero nella laguna. \\
\hline $\begin{array}{l}\text { O senhor Kaputu Kinjila, } \\
\text { com as algibeiras cheias de dinheiro, } \\
\text { comprou a morte; }\end{array}$ & $\begin{array}{l}\text { Il signor Kaputu Kinjila, } \\
\text { con le tasche piene di soldi, } \\
\text { comprò la morte: }\end{array}$ \\
\hline $\begin{array}{l}\text { o senhor Kambaxi Kiaxi, } \\
\text { com as algibeiras } \\
\text { cheias de nada, salvou a vida. }\end{array}$ & $\begin{array}{l}\text { il signor Kambaxi Kiaxi, con } \\
\text { le tasche piene di niente, ha avuto } \\
\text { salva la vita. }\end{array}$ \\
\hline Por isso & Per questo \\
\hline canta: & canta: \\
\hline Kalumbinga kia Kinjila & Kalumbinga kia Kinjila \\
\hline Kinjila uadiboto & Kinjila uadiboto \\
\hline Kalumbinga kia Kinjila & Kalumbinga kia Kinjila \\
\hline Kinjila uadibondo... & Kinjila uadibondo... \\
\hline $\begin{array}{l}\text { E os esporões respondem: } \\
\text { Kia' xi, kia' xi }\end{array}$ & $\begin{array}{l}\text { E gli ossicini rispondono: } \\
\text { Kia' } x i, \text { kia' xi }\end{array}$ \\
\hline Kia bulu, kia mulenge*. & Kia bulu, kia mulenge*. \\
\hline Tenho dito. & Questo ho detto. \\
\hline $\begin{array}{l}\text { * O corninho (esporão) do Kinjila / Kinjila } \\
\text { perdeu o valor / O corninho (esporão) do } \\
\text { Kinjila / Kinjila faliu / / ... O que é da } \\
\text { terra, é da terra / O que é do céu, é do } \\
\text { vento }\end{array}$ & $\begin{array}{l}\text { * L'ossicino di Kinjila / Kinjila ha perso il } \\
\text { coraggio / L'ossicino di Kinjila / Kinjila } \\
\text { ha fallito / / ... Ciò che è della terra, è } \\
\text { della terra / Ciò che è del cielo, è del } \\
\text { vento }\end{array}$ \\
\hline
\end{tabular}

